\title{
On Kant and Husserl on Transcendental Logic
}

\author{
Mohammad Shafiei ${ }^{1}$ \\ Ahmad Aliakbar Mesgari ${ }^{2}$
}

To appear in Synthese; please quote published version.

\begin{abstract}
It is well known that the notion of transcendental logic has a prominent role in both Kant's and Husserl's theories of knowledge. The main aim of the present paper is to study the links between formal and transcendental logic in Husserl on the one hand, and the links between general logic and transcendental logic in Kant on the other. There is a debate about the proper relation between transcendental logic and general logic in Kant's philosophy. By means of our definition of transcendental logic, mainly drawn from Husserl's analyses, we will try to offer an appropriate interpretation of Kant's view.
\end{abstract}

Keywords: Transcendental logic, Formal logic, General logic, Kant, Husserl, Phenomenology

Authors wish to thank Shahid Rahman, Mark van Atten, Carlos Lobo, Hassan A. Shirazi and two anonymous referees of Synthese for valuable comments on earlier versions of this paper. This work has been done as a part of first author's postdoctoral project funded by Iran's National Elites Foundation (INEF).

\footnotetext{
${ }^{1}$ Department of Philosophy, Shahid Beheshti University, Tehran, Iran Mohammad.Shafiei@mailx.univ-paris1.fr

2 Department of Philosophy, Shahid Beheshti University, Tehran, Iran a-aliakbar@sbu.ac.ir
} 


\section{Introduction}

Both Kant and Husserl make reference to 'transcendental logic', and this notion plays a prominent and distinctive role in their philosophies. However, considering the substantial developments in logic since their times, and the concomitant evolution of the common concept of logic, one may reasonably ask what the term 'logic' means in the expression 'transcendental logic'. In what sense it is a logic, if indeed it is?

The question can be cashed out as the following: Is 'transcendental logic' supposed to be a specific branch of logic? Is it intended to develop a particular logical system? Or is it supposed to offer a different approach to logic, or, at least, to enrich our conception of logic as such?

It seems at first glance that 'transcendental logic' must be of the third sort. That is, first of all, we are to encounter a peculiar conception of logic. However, it is also possible that such a conception contains a normative standpoint that endorses a particular logical system, or rather contributes to developing such a system: this depends on our delimitation of transcendental logic, or rather on the delimitation that transcendental logic proposes for logic as such and the task that it accordingly sets for itself within this delimitation.

In this paper we first examine the phenomenological conception of transcendental logic, and then compare it with Kantian conception, discussing the status of transcendental logic as compared to formal logic. There is a debate about the proper relation between transcendental logic and general logic in Kant's philosophy, as recently discussed by Tolley (2012). By means of our definition of transcendental logic, we will try to offer an appropriate interpretation of Kant's view.

\section{Phenomenological conception of transcendental logic}

According to the general phenomenological distinction between act and product, 'a sharp distinction must be made' between thinking and thought (Husserl 1969: 25). On the one hand, we have the activity of thinking - judging, for example - with all its intentional characters as well as psychological bindings and, on the other hand, we have thoughts - e.g. judgments - as the products of those activities. In the original activity of reasoning, so Husserl argues, we bring 
about as products, not only the consequent judgments but also the patterns of thinking or the logical formations (Husserl 1969: 166, 264). Such formations, though produced in the concrete activities, 'transcend the current sphere of presence to consciousness' (Husserl 1969: 33) and are a priori as they are 'pure from all empeiria' (Husserl 1969: 29). Thus, those formations, considered as ideal products, are genuinely objective.

Logic, in one sense, seeks to deal with those objective formations in order to elaborate them as principles or rules which are to be formal conditions for judgments and inferences. Husserl calls this objective logic. ${ }^{3}$ Traditional logic and also modern mathematical logic are then objective logics, since they are supposed to deal with the objectification of the laws and rules which are functioning in reasoning. Objective logic, or formal logic, takes the rules and principles of reasoning as consisting an objective field of study abstracted from any subjective act.

Now, on a higher level, a field of study should be defined which is concerned with the origins of the logical issues mentioned above. This studies both the objective and subjective sides of logic in their correlation. This discipline is called transcendental logic.

Husserl says:

Logic, as the science of all the logical as such and - in its highest form, which embraces all other forms of the logical - as the science of all science as such, inquires in two opposite directions. Everywhere it is a matter of rational productions, in a double sense: on one side, as productive activities and habitualities; on the other side, as results produced by activities and habitualities and afterwards persisting. (Husserl 1969: 33)

Objective logic, as a study which deals merely with the formations - that is, the results of the activities of reasoning - is not concerned with the roots of such formations or the conditions of their presence in consciousness. On the other hand, the study of those productive activities would belong to psychology if the objective side stayed out of the sight. That is to say, a merely subjective logic, which only investigates the subjective, in the sense of the psychological, issues involved in reasoning, would not suffice to study the transcendental status of reasoning, which

\footnotetext{
${ }^{3}$ This term is used by Husserl in a completely different way than as employed by Hegel. Peirce also uses this term in his classification of sciences, in a yet different way. See (Peirce 1976: 30).
} 
should also investigate the constitution of logical objectivities, and thus comprises "senseinvestigations concerning with formal logic" (Husserl 1969: 12).

The ultimate task of logic, which belongs to the transcendental, two-sided logic, is described by Husserl as follows:

[W]ith a continuously two-sided research (results on either side determining inquiries on the other), logic must go back systematically from the ideal formations to the consciousness that constitutes them phenomenologically; it must make these formations understandable, in respect of their sense and their limits, as essentially products of the correlative structures of productive cognitive life ... . The ideal Objectivity of the formations with which logic is concerned - like the real world - is in no way altered in the process. (Husserl 1969: 263)

In order to explain what is sketched above, which is based on Husserl's arguments in Formal and Transcendental Logic (Husserl 1969), the following can be offered which puts together ideas from throughout Husserl's works. Pure logic is the theory of science in general (Husserl 2001: 16). To the idea of science in general "belongs, first of all, an initial clarification of 'judicative" doing and the 'judgment' itself, along with the discrimination of immediate and mediate judgments" (Husserl 1960: 10). "Mediate judgments, the conclusion of an inference, for example, are results obtained from grounds which themselves refer back to immediate cognition" (Husserl 1973: 24). A main concern of science is to ground mediate judgments on the basis of immediate judgments (Husserl 1960: 10). Thus the theory of science in general, detached from the particular contents with which judgments of any science deal, concerns itself with the conditions of such a grounding. If all judgments we could have were immediate or intuitive, in the phenomenological sense of the term, there would be no room for mediate grounding, that is, for reasoning, and thus no logic could be brought about. In fact, in such a case no science, or at least no eidetic science, could exist and a fortiori no theory of science would be possible. For example, if all we knew about the relation between numbers were as immediately conceived as is the case for the few first ones, "there would be no arithmetic, for it would then be completely superfluous" (Husserl 2003: 201).

But how does the grounding of a mediate judgment on the basis of immediate ones work? A distinctive kind of grounding is the one based on the forms of the judgments involved. Forms of judgments, as ideal entities, are objective in their own right. Where logic deals with such forms 
in order to establish certain kinds of grounding - above all, deduction, in which the relation of grounding is a necessary one - it should be called formal logic. Formal logic, in dealing with the objective forms of judgments and disregarding the constitutional root of those forms in subjective acts of reasoning and judicative doing, is called by Husserl objective logic.

However, logic as such is not restricted to formal relations. If logic is to deal with reasoning, that is, a certain kind of grounding of knowledge (Erkenntnisbegründung) then it primarily has to study all kinds of mediate grounding. It is not the case that any grounding as such has to wait for a reasoner to entertain some preconceived formal rules of grounding. Such formal rules are obtained by the thinking subject from certain primordial acts of reasoning. Just as the categorial forms of judgment themselves may be grasped or constructed by the thinking subject in this or that manner (that is, either by ideation or categorial intuition or by categorial synthesis), ${ }^{4}$ one may discern the formation involved from within the originary reasonings. In a higher act, the thinking subject can examine whether those formations have any role in the grounding of the judgments attained. That is, the thinking subject may identify the patterns of reasoning which can be abstracted from the content and yet constitute such a connection between forms of judgment that can be a ground for conclusive reasoning. Such a move must of course be subject to a critical examination, which is not to recall some predetermined, objective criteria but to explore certain peculiar acts of subjectivity. Therefore a field of study, in regard to judgment grounding or reasoning in general, is opened which is essentially a self-investigation of the transcendental subjectivity. This is what is called by Husserl transcendental logic.

A further explanation about the notion of grounding may be helpful to clarify the nature of transcendental logic. For Husserl every cognition must be grounded. What is not directly grounded in evidence must be mediately so grounded and all must finally rest upon apodictic grounds. Moreover, "absolute grounding of cognition is possible only in the all-embracing science of transcendental subjectivity, as the one absolute existent" (Husserl 1969: 271). Now not only must any mediate judgment be grounded on some supposedly evident judgment, which its formulation is the task of formal logical, logic itself must be grounded finally in transcendental subjectivity. This subjective ground of logic is to be clarified by the selfexamination on the part of transcendental subjectivity and the specific discipline so defined is called transcendental logic.

\footnotetext{
${ }^{4}$ We explain these notions further in section 4.
} 
It is worth mentioning here that although any logical knowledge must finally rest upon apodictic grounds, apodicticity does not entail infallibility (Husserl 1969: 156). Or, as David W. Smith (2004: 54) puts it, the phenomenological character of apodicicity, that is, indubitability, should not be confused with the ontological character of infallibility.

\section{The status of transcendental logic in Kant}

What has been explained above is indeed very similar to Kant's conception of transcendental logic:

It [i.e. transcendental logic] would therefore concern the origin of our cognitions of objects in so far as that cannot be ascribed to the objects; while general logic, on the contrary, has nothing to do with this origin of cognition, but rather considers representations, whether they are originally given a priori in ourselves or only empirically, merely in respect of the laws according to which the understanding brings them into relation to one another when it thinks, and therefore it deals only with the form of the understanding, which can be given to the representations wherever they may have originated. (Kant 1998: A55-6, B80)

However, there are some issues that make it difficult to give an indisputable interpretation of Kant's transcendental logic. This is due, above all, to the fact that very fundamental problems are discussed by Kant under the title of transcendental logic. As is clear from the above quotation, unlike Husserl for whom both formal and transcendental logics are concerned with 'formations ${ }^{5}$, the former dealing with them as objects and the latter dealing with their constitution in consciousness, Kant brings in more general problems concerning the origin of the 'cognition' of

\footnotetext{
${ }^{5}$ As an exemplary evidence that for Husserl "formation" is the central theme of logic, either formal or transcendental, we may bring the following quotation:

The formations with which logic is concerned and their universal forms are given at first in a straightforward evidence; and this comes first necessarily. But now [i.e. in transcendental logic] a thematizing reflection on this evidence is demanded: a reflection, that is, on the formative activity, which has heretofore been carried on straightforwardly and naively, without becoming a theme. The formations and universal forms (formations belonging to a higher level), which are "given" in the activity and are at first, all that is "given", must now be "clarified" reflectively in order that, by clearing up the intentionality that aims at and actualizes its objective sense originaliter, we may rightly apprehend and delimit this sense and secure its identity against all the shiftings and disguisements that may occur when it is aimed at and produced naively. (Husserl 1969: 176)

Therefore, although Husserl's transcendental logic, just like Kant's, deals with the problem of "origin", it characteristically focuses on the origin of formations. The basic difference, however, is that those formations for Husserl are genuine objects while this is not the case for Kant. We discuss more about this point in the next sections.
} 
objects. The greater part of Kant's Critique of Pure Reason falls under the title 'transcendental logic'. In addition, in certain places of his work, Kant gives definitions for transcendental logic which may, at least at first sight, to seem in tension to each other. Historically there have been two main interpretations of Kant's account of transcendental logic and its relation to general logic.

Some commentators on Kant, based on certain textual evidence, defend the view that transcendental logic should be distinguished from general logic by the new domain that it opens. Whereas general logic deals with analytic judgments, transcendental logic has as its scope the species of synthetic judgments. Tolley (2012) calls this view domain-exclusive. As he observes, such an interpretation is defended by Friedrich Ueberweg (1874), Hermann Cohen (1885), and Norman Kemp Smith (1918). Notable evidence for this view comes is the following quotation:

The explanation of the possibility of synthetic judgments is a problem with which general logic has nothing to do, indeed whose name it need not even know. But in a transcendental logic it is the most important business of all, and indeed the only business if the issue is the possibility of synthetic a priori judgments and likewise the conditions and the domain of their validity. For by completing this task transcendental logic can fully satisfy its goal of determining the domain and boundaries of pure understanding. (Kant 1998: A155, B194)

Other commentators, pointing to other textual evidence, hold the view that transcendental logic, studying only synthetic a priori thinking, is a branch of general logic which concerns all thinking. Such a view has been argued for by H. J. Paton $(1936,1958)$. Tolley calls this the domain-subordinative view. As an example of a quotation to support such a view we may mention the following:

$[T]$ ranscendental logic ... has to do merely with the laws of the understanding and reason, but solely in so far as they are related to objects a priori and not, as in the case of general logic, to empirical as well as pure cognitions of reason. (Kant 1998: A58, B81-2)

Both of those views try to delimit transcendental logic by means of its domain or scope. However, if we characterize transcendental logic in the way presented above we might see that the disagreement between the interpretations is based rather on the ambiguity of the concept of 
the domain while speaking of logic. We will discuss this point in the following, and hence argue for the view that Kant's conception of transcendental logic is in its essence the same as the Husserlian conception explained above. The differences between Kant's and Husserl's account can be specified once the common conception is grasped. We will examine those differences in the next section.

Any science normally has its own subject matter, that is, a domain of objectivity about which it is supposed to give knowledge. Logic as a science has an extra feature: it is supposed to be applied in domains of objectivity. Logic may be used as a tool, though not a productive one, in the course of seeking knowledge. In this sense it is relevant to speak about the topics in thinking and reasoning about which a logic is useful or usable. Therefore, while speaking about the object of logic we should distinguish between two things: a domain of objectivity about which a logic is to give knowledge, and a domain on which a logic may be applied. Let's call the former the subject matter and the latter the domain.

General logic as a negative tool seems to give no objective knowledge. However, since general logic's being conditio sine qua non, according to Kant, ultimately rests upon the principle of non-contradiction, which is 'the universal and completely sufficient principle of all analytic cognition' (Kant 1998: A152, B192), it is also capable of giving knowledge about analytic cognitions, that is, it is also to produce analytic judgments. As Kant says:

[I]f the judgment is analytic, whether it be negative or affirmative, its truth must always be able to be cognized sufficiently in accordance with the principle of contradiction. (Kant 1998: A152, B191)

Therefore, general logic is not completely without subject matter: rather, its subject matter is analytic cognition. Its domain, on the other hand, is any objectivity whatsoever. If general logic is employed as it should be in general, that is as a negative tool, or as Kant puts it as a canon not as an organon, it can be applied everywhere.

The subject matter of transcendental logic, as the structure of Critique of Pure Reason shows, is the functions of understanding and reason and their principles - and this includes also the principle of non-contradiction. Transcendental logic thus gives knowledge about the origins of both analytic and synthetic judgments. Therefore, in respect with the subject matter, general logic is subordinated to transcendental logic. However, as a task of study, the origin of synthetic judgments is much more important for transcendental logic. For this reason the proponents of the 
domain-exclusive view are justified in emphasizing that transcendental logic deals with synthetic cognitions and general logic with analytic ones. Nevertheless, it is wrong to state that their subject matters are mutually exclusive. As is clear from the aforementioned quotation, Kant says that 'The explanation of the possibility of synthetic judgments ... in a transcendental logic is the most important business of all'; the most important business, not the only one. It is the 'only' business only when 'the issue is the possibility of synthetic a priori judgments' (Kant 1998: A155, B194). Then transcendental logic also deals with the possibility of analytic judgments and their origin, but since this is not as problematic as synthetic judgments, and also because there is already a formal system, a complete one in Kant's eyes, dealing with it, a little part of transcendental logic is dedicated to it.

The domain of transcendental logic is, however, very restrictive. If one wants to use the methods of transcendental logic to draw out a piece of knowledge, one should have in mind that it is applicable only to a priori cognition. Properly speaking, transcendental logic deals with originations not with the objective consequence relations. Yet if logic is used as a propaedeutic, general logic is unrestricted in its domain and it is propaedeutic to all use of the understanding in general, while transcendental logic is connected only to the pure a priori cognition (Kant 1992: 530). Then there is a sense in which the domain of transcendental logic is subordinated to that of general logic. Therefore, the domain-subordinative view is not totally groundless. However, transcendental logic should not be characterized by its domain since it is not specified by its domain of objectivity but above all by its subject matter, which is so fundamental that is at work in every cognition of objects.

Kant says:

In a transcendental logic we isolate the understanding ... and elevate from our cognition merely the part of our thought that has its origin solely in the understanding.

(Kant 1998: B87)

This may suggest that in transcendental logic we do not deal with any thinking whatsoever, but only with one kind of it, and thus transcendental logic is not general. But we should notice that Kant says that in transcendental logic we deal with a particular part of our thinking, while this part may be present in every judgment and indeed it is. So, the fact that the domain of transcendental logic is restricted in a sense does not mean that it is not general. 
Tolley (2012) argues that the difference between transcendental logic and general logic is not a matter of domain but one of aspect. Accordingly, he states that transcendental logic is as general as general logic; this is true, as we just tried to explain. We are in agreement with Tolley that the difference between transcendental logic and general logic should be sought in terms of aspect rather than domain. However, we shall disagree with his proposal on what aspects are to characterize each one of those logics. The difference of the aspects that he suggests is based on the difference between form and content. He links general logic with the form and transcendental logic with 'the content of thinking and judging, albeit in a very abstract manner'. An apparent problem may arise here, which Tolley himself mentions and tries to resolve, if we understand the form/content distinction in the way Kant himself uses it. For Kant, form is what is introduced by understanding while content is given in intuition. In other words, form is intelligible whereas content is sensible. Of course it would be quite wrong to say that transcendental logic concerns the sensible. Tolley made it explicit that here the form/content distinction should be regarded as both belonging to the conceptual side of cognition ${ }^{6}$. In this sense he speaks of content in a very abstract manner'. However, another problem would arise here, which Tolley does not point out. A usual way of conceiving of the distinction between content and form as regards conceptual cognition is to see the categorial articulation of the cognition as form and its constituting parts (which might be articulated in this or that manner) as content. This is in connection with what was known from the medieval era as the distinction between matter and form in logic. In this view, the form of a judgment is made up of its syncategorematic parts. Its matter is its purely cetegorematic terms. We find such a definition, for example, in Buridan (2015: 74), who says that in the judgment "all humans are mortal", for example, "all ... are" and thus "all" and "are" constitute the form of judgment, whereas "human" and "mortal" are meanings which provide the content of judgment. Here we are concerned with "conceptual content", as Tolley calls it, and he shows convincingly that it was an important theme for Kant. However, the problem is how we can say that transcendental logic solely concerns itself with the conceptual content of cognition so that the issues of form remain outside of its scope? If the difference between form and content is what is supposed to characterize general and transcendental logic in contrast to each other,

\footnotetext{
${ }^{6}$ In our examination of Tolley's argument, we shall leave the discussion on the distinction between the conceptual and the non-conceptual in the sphere of cognition. This is a very important topic in its own right. However, we may mention, in passing, that Husserl's theory of noema deals with the problems pertaining to this topic, and, although there are different interpretations of noema, it can be said that the "noematic" in Husserl is broader than the "conceptual" in Kant.
} 
then if the issues of form pertain to general logic they should be excluded from the task of transcendental logic. But we frequently see in Kant that transcendental logic is to deal with the origin of cognition, which of course includes its form, and also that transcendental logic is to explain the possibility of synthetic judgments and thus not only their conceptual content but also their form. Above all, the parallelism so rightly stressed by Tolley between forms of judgment, dealt with in general logic, and the table of categories, would be lost if we render the distinction between general logic and transcendental logic as equivalent to the distinction between syncategormatic and categorematic terms. Indeed, in the table of categories we still deal with forms, but here as originated in the transcendental subjectivity. We find Tolley's content/form argument unconvincing, because in transcendental logic too we deal with the forms of judgment, particularly with the statuses and the origins of those forms. The distinction, as our explanation in the previous section shows, is that in general, formal logic we deal with the forms as objective, and in transcendental logic we deal the transcendental-subjective ground of the same forms.

If the delimitation of logical studies given in the previous section is taken into account, most of tensions concerning the proper interpretation of Kant's conception of transcendental logic would be resolved. It will be clear that transcendental logic is neither a specific part of logic nor is it to be a system of logic focusing on a domain other than that of formal logic. Rather, it introduces a new conception of logic, or to put it better, it explores a higher perspective toward the logical elements and the associated problems so that although the general logic may remain, in Kant's eyes, unaltered, our understanding of its nature would be radically changed. Then, transcendental logic need not be a new part or an alternative system designed to say something about logic. It concerns the origins, and in this sense it is already on a different level than that of general logic.

Yet the question of whether from this perspective we have only a descriptive stance toward the objectivities formulated in general logic, or also a prescriptive stance, which provides some criteria to revise, or at least evaluate, general formal logic, remains a matter of debate. Kant explicitly takes the former position, whereas Husserl's view is at least open to the latter position. The reason for this rests upon a very basic difference between Kant and Husserl, discussed in the following section. 


\section{The difference between Kant's and Husserl's views}

In the about one century distance between Kant and Husserl, formal logic had been developed extensively ${ }^{7}$ and especially Husserl wrote in the era of intensive developments in modern logic. However, Husserl's account of transcendental logic already stands apart from that of Kant. In what follows I discuss the main point of difference.

For Kant, intuition is restricted to the sensible. Therefore the ultimate formations of judgments, namely the categories, being formations which originate in the understanding and thus are not intuitable, need to be validated by a particular method which is called 'transcendental deduction'. The objective validity of the categories cannot be grounded in direct experience, that is, in what Kant calls 'empirical deduction' (Kant 1998: A86, B118). Accordingly, such transcendental deductions are 'once and for all'. In the discovery of categories, the forms of judgment as already formulated in general logic may serve as clues and in turn the transcendental deduction may grant the validity of those formations. Once such validity is granted, there is no room for alteration - unless we find we had committed an error. Kant speaks of a list of categories which is to be explored once. Thus general logic, if correct that is, if its forms are coincident with the a priori concepts of understanding - is complete. In other words, there is no place in Kant's philosophy for "the critical view of logic", as it is also recently discussed by Hartimo (2019)8. Whereas Kant's critical philosophy is to study conditions of the possibility of experience, which are at the same time conditions of the possibility of the objects of experience (Kant 1998: A112), logic and logical entities are not considered by Kant as proper objects of experience and thus no critical view is aimed at them. For Husserl such exclusion is unjustified. It can be said that if "critical" view, in the Kantian sense of the term, is developed accurately to cover also logic, it leads to "transcendental logic" in the Husserlian sense of the term. Nevertheless, as we will see, it is not an accidental feature of Kant's philosophy not to extend its critical view in this direction. For Husserl, the intuition may

\footnotetext{
${ }^{7}$ Sometimes it is said that modern logic was born in 1879 by Frege's work. But one should not overlook Peirce's works at the same time, and the groundbreaking works of Boole and Bolzano before them, not to mention other names which have had decisive contribution to shaping modern logic.

${ }^{8}$ Our analysis here about the difference between Kant's and Husserl's take on logic is basically in accordance with that of Hartimo (2019), save for the fact that she concentrates on the relation between formal logic and mathematics (and thus formal ontology) and shows the main discordances of Husserl and Kant, whereas we here try to show the divergences only focusing on the relation between formal logic and transcendental logic. The relation between logic and ontology is a significant theme of Husserl's phenomenology dealing with which is beyond the task of this paper.
} 
also be extended to the categorial forms. The categories, as discussed below, can be grasped through experience. Accordingly, although Husserl speaks of certain categories ${ }^{9}$, he does not consider a central task of philosophy to offer, a priorily, a closed list of categories; rather what should be pursued is to study categorial acts and especially categorial synthesis. ${ }^{10}$ As we will see, these are important points which affect the analysis of the relation between the transcendental and formal logics.

To have a clear idea of the difference between Kant's and Husserl's views on logic, we may first quote Kern, who in his outstanding work Husserl und Kant dedicates a chapter to the idea of logic. He states:

Kant's explanation that the Reason in formal logic does not deal with the objects, but only with itself, is a false explanation according to Husserl, if he understands the expressions in his own senses. The 'meanings' in the apophantics, as well as 'something' in mathematics, are for him objects in the true sense of the word. Whereas, if he reads Kant's explanation in the Kantian sense, where 'object' means only a really existent object, he could agree with Kant. (Kern 1964: 139)

That Husserl considers logical forms to be genuine objects and accordingly extends the scope of intuition up to the categories, whereas Kant does not, reflects the difference in their views on the status of intuition. Kant makes a contrast between intuition and understanding, and thus the categories, or the most general concepts belonging to the realm of understanding, fall outside of the scope of intuition. For Husserl the notions of intuition and understanding are not defined in this Kantian way. The notion of intuition is explained in terms of the fundamental concept of intentionality. Since every conscious act is intentional, Husserl introduces the notion of intuition in connection to the direct fulfillment of the intention. An intention may be unfulfilled and intend object in a way which Husserl calls signitive (Husserl 2001: 710). Otherwise, it may be already fulfilled. In this case we have an intuitive intention. Accordingly, two kinds of fulfillment should be distinguished: in the static union of intuition the intention is already fulfilled, while in the dynamic union of intuition there is a primary distance between an empty intention and the fulfilling experience. Even in the case in which the intention is already fulfilled, an empty

\footnotetext{
${ }^{9}$ For a thorough study on the system of Husserlian categories see (Smith 2013).

${ }^{10} \mathrm{He}$ explores those notions, most importantly, through the sixth investigation of Logical Investigations (Husserl 2001) and in section 9 of Ideas II (Husserl 1988).
} 
intention can be grasped by means of empty-modification ${ }^{11}$. To the side of intention belongs categorial articulation of an experience in contradistinction with its 'receptive givenness'. Categorial articulations are brought about by spontaneous acts of subjectivity, in contrast to receptivity, and belong to a new kind of objectivity (Husserl 1973: 198-9). Categorial objectivities are called by Husserl objectivities of understanding ${ }^{12}$. Therefore, according to Husserl, understanding is related to having an empty intention regardless of its possible content. In other words, to have understanding is to have access to meaning, or to the meaning-based essence ${ }^{13}$ of intention, independent of the actual access to the possible intuition corresponding to that intention.

Now, as intuition is constituted in connection to the direct fulfillment of intention, we may investigate if it is plausible to speak of the intuition of the ideal, including the categories. Since the ideal objects are objectified, as it should be, by some intentions, and those intentions are in these cases fulfilled as the moments inherent in the categorial experience (that is, the experiences in so far as they are categorially articulated, or more simply the experiences with conceptual content), then we are able to speak of the intuition in the case of the ideal objects. The fulfillment of the intentions toward the ideal cannot be reduced to some sensuous elements, thus they are fulfilled exactly as the fulfillment of categorial intentions, hence the idea of categorial intuition (Husserl 2001: 803).

Such a fulfillment is primarily a moment within the conceptual experiences. However, in a higher act such a moment can be reflected upon (Husserl 2001: 815). In this case we will have a particular sense of categorial intuition, which is the intuition of categories, or of the ideal. This is a delicate point and we cannot here go into the details. ${ }^{14}$ However, we may say in passing that for Husserl the categorial forms are possibly given in experience in a way analogous to common sensuous intuition (Husserl 2001: 784). A central case of categorical intuition is ideation or essence-seeing (Wesenschau). As an example of ideation consider the judgment "there are two green tables". Provided that the color green and the shapes of the tables are given through sense-

\footnotetext{
${ }^{11}$ Leermodifikation. See (Husserl 2002: 96)

${ }^{12}$ Verstandesgegenständlichkeiten. A chapter of Experience and Judgment is dedicated to explain the constitution of objectivities of understanding (Husserl 1973: 237-271)

${ }^{13}$ Bedeutungsmäßigen Wesen. See E. Husserl, Logische Untersuchungen, Zwiter Band, I. Teil. (Husserl 1913: 150, 417, 436).

${ }^{14}$ For the literature on the adequate understanding of categorial intuition, see (Tugendhat 1967), (Sokolowski 1974:34-42), (Sokolowski 1981), (Lohmar 2002), (Lohmar 2006), (Hopkins 2011), (van Atten 2015b), and (Shafiei 2018: 118-138).
} 
perception, what brings about the notion of "two"? Husserl shows, in the Prolegomena and elsewhere, the flaws of the theory of abstraction as to explain the origin of ideal concepts. In his theory of ideation Husserl explains that how ideal concepts, including also certain logical connectives, are obtained within an experience by means of some specific acts. Therefore, ideal objects are objects in their own right and can be investigated by means of appropriate eidetic experiences.

The ultimate disagreement of Kant and Husserl about formal logic here shows itself. Husserl says that Kant's position largely involves a reaction to Hume and other empiricists. But via such a reaction, however elegant it is, certain prejudices have found their way into Kant's philosophy. One of those prejudices is the overlooking of ideal objects as genuine objects. Husserl says:

The eighteenth century and the age that followed were so strongly actuated by empiricism (or better, by anti-Platonism) that nothing was remoter from them than recognition of ideal formations as being objectivities - in the manner and in the good and never-relinquishable sense whose legitimacy we have established in detail. (Husserl 1969: 258)

Having failed to notice the objectivities peculiar to formal logic, Kant 'asked no transcendental questions about formal logic, but rather ascribed to it an extraordinary apriority, which exalts it above such questions.' But how could such negligence on the part of Kant have taken place?

How does it happen that he [i.e. Kant] regards a formal logic, with its apriority, as self-sufficiently grounded? How is it comprehensible that he never thought of asking transcendental questions about the sphere of formal logic, taken as a sphere in and for itself? That can be understood as a consequence of the above-mentioned dependence on Hume implicit in Kant's reaction against him. Hume directed his criticism to experience and the experienced world, but accepted the unassailableness of the relations of ideas (which Kant conceived as the analytic Apriori). Kant did the same with his counter-problem: He did not make his analytic Apriori a problem. (Husserl 1969: 260)

As a consequence of the empiricists' and Kant's attitude, no fundamental investigation into the origin of formal logic was undertaken. According to Husserl: 
That was because no one ventured, or had the courage to venture, to take the ideality of the formations with which logic is concerned as the characteristic of a separate, self-contained, 'world' of ideal Objects and, in so doing, to come face to face with the painful question of how subjectivity can in itself bring forth, purely from sources appertaining to its own spontaneity, formations that can be rightly accounted as ideal Objects in an ideal 'world'. (Husserl 1969: 260)

This latter sentence, as we have mentioned before, is the principal question of transcendental logic for Husserl. So, the main difference between Kant and Husserl is that Husserl emphasizes the objectivity of ideal formations so that the task of transcendental logic is to investigate those objectivities and to unveil their genesis and the truths about them. Thus the origin and the validity of formal logic are to be explored by transcendental logic. Transcendental investigations will provide us with the criteria to assess or possibly to revise a given formal logic. If we found no ground for the validity of a logical formation in our transcendental-intentional experience, no transcendental argument, in the Kantian sense, can be helpful: such a formation should be put aside from formal logic or it should be restricted in a proper manner.

Therefore, formal logic, formulating the ideal relations between some categorial forms, not only is devised in order to be applied in the course of knowledge but also is the representation of the knowledge about certain ideal objects. ${ }^{15}$ The investigations pertaining to transcendental logic lead Husserl to distinguish three levels of formal logic (Husserl 1969: 48-55):

1. Pure morphology of judgment

2. Logic of consequence

\section{Logic of truth}

The logic of consequence, which formulates the analytic consequence relation, is also called the logic of non-contradiction. That Husserl also adds the first and the third level to formal logic besides the level of non-contradiction, which seems to be equal to Kant's conception of general

\footnotetext{
${ }^{15}$ One may note here that for Husserl the formality of formal logic does not mean that it is devoid of any content. In this regard, Husserl's account of formal logic is in agreement with that of Frege. MacFarlane (2002), in his thorough study of Frege's conception of logic in comparison to that of Kant, says:

[L]ogic, for Frege, cannot abstract from all semantic content: it must attend, at least, to the semantic contents of the logical expressions, which on Frege's view function semantically just like non-logical expressions. And precisely because it does not abstract from these contents, it can tell us something about the objective world of objects, concepts, and relations, and not just about the "forms of thought."
} 
logic, should be clear from the above explanations about the objectivity of logical forms. If logical forms are genuinely objective we may speak about truths concerning them, not only the truths for which they are supposed to serve as forms. Kant would assign no place for the logic of truth in his general logic, for he does not consider logical forms as Objects, and so to speak about them would not be legitimate except by means of the transcendental argument (in the Kantian sense of the term).

Since a main point of divergence between Husserl and Kant, as just explained, is their account about the objectivity of the ideal, questions will arise about the exact nature of the ideal objects and their ontological status in Husserl. The answer lies in Husserl's theory of meaning which itself depends on his theory of intentionality. Therefore we need to have a brief survey on this matter before concluding our discussion. Of course this is itself a vast topic and no comprehensive treatment is possible here. We only outline below the main points which are directly relevant to our argument. ${ }^{16}$

\section{Logic and theory of meaning}

It may be inferred from Husserl's triple distinction of the levels of formal logic, mentioned above, that, since it includes logic of truth, Husserl's account of formal logic already encompasses a form of semantics. This is true, but it only expresses one side of the matter. Logic, as said above, concerns truth in two senses. One is the question regarding the truth of propositions consisting a logical inference. This is the question with which semantics is to deal. ${ }^{17}$ From the phenomenological point of view truth of propositions should be explained in terms of intentionality, that is, as a relation of fulfillment between some sorts of intentions (here of the propositional form) and what fulfill them. Husserl developed a full-fledged theory for such a relation already in his Logical Investigations. The other possible sense is the question regarding the truths of logical principles, here considered not as tautologies in the sense of devoid of any content. If ideal objects, including logical forms, are proper objects, then there are intentions toward them which may be fulfilled or not, that is, it would be relevant to ask about the truth of

\footnotetext{
${ }^{16}$ For a recent and detailed analysis of the phenomenological theory of meaning and intentionality see (Shafiei 2018).

${ }^{17}$ This formulation would be appropriate only for model-theoretic semantics. For other frameworks some modifications are needed.
} 
statements about logical forms: they are not only supposed to be truth-preserving but must be true themselves.

For Kant, transcendental logic comprises a logic of truth (Kant 1998: A62-3/B87) as is the case for Husserl. The difference is that, by distinguishing the truth level of formal logic, Husserl highlights a link between formal logic and transcendental logic which can be seen as constituting another locus for the normative standpoint of transcendental logic toward formal logic. In the other words, formal logic for Husserl is not an autonomous enterprise whose validity lies only on its self-consistence. Rather it owes its authenticity to the transcendental sense-investigations pertained to it. This method of sense-investigation (Besinnung) is essential for any science; and logic is no exception ${ }^{18}$. Indeed this question is much more significant for logic for its being the general theory of science.

Logical objects are in need to meaning clarification; their constitution as ideal objects, as dependant or independent meanings, must be made explicit by means of transcendental investigations. Truths about them, i.e. logical principles, should be drawn from those investigations; or the received principles must be thus reevaluated. The constitution of meaning, according to phenomenology, depends on intentionality. In order to grasp the aforementioned ideas regarding the relationship between formal logic and truth, it is essential to keep in mind that Husserl would not admit any kind of truth-theoretical theory of meaning. This point has been discussed elsewhere (Shafiei 2018 and 2019) but in nutshell it is because intention cannot be reduced to the features of fulfillment.

Whereas for Kant "Our sensible and empirical intuition alone can provide them [concepts] with sense (Sinn) and significance (Bedeutung)" (Kant 1998: B149), for Husserl this is the intention which provides meaning (Bedeutung), and thus in order to validate a conceptual enterprise one should not depend only on its "safe" application or inner consistence; rather one should establish it by turning toward the transcendental intentionality. If formal logic were to get its authenticity from its application and from its being self-consistent, transcendental logic would have nothing to do with its constitution, but since, according to Husserl, this is not the case transcendental logic may take a normative standpoint toward formal, or general, logic. ${ }^{19}$

\footnotetext{
${ }^{18}$ For a clear explanation of the place of Besinnung for Husserl see (Hartimo 2020).

${ }^{19}$ It is a matter of debate among Husserl scholars whether his transcendental approach would lead to a revisionist position with respect to sciences or remain conservative. For the reasons discussed above we side ourselves with
} 


\section{Conclusion}

Transcendental logic is the study of the origins of the constituents of formal reasoning. In this sense it is a two-sided study. It investigates 'productive activities and habitualities' functioning in reasoning as well as the patterns of inferences, 'produced by activities and habitualities and afterwards persisting'. The subject matter of transcendental logic is the constitution of all kinds of formations, not only that of analytic judgments. The subject matter of general logic is analytic cognition. Therefore, in regard to the subject matter, general logic is subordinated to transcendental logic. On the other hand, general logic as containing the formal rules of reasoning is to apply in every domain of objectivity, whereas transcendental logic is not to apply in some places, and its proper domain is that of a priori cognition. So far Husserl and Kant could concur. The disagreement is that whereas for Kant general logic is complete and transcendental logic stands only in a descriptive position to it, for Husserl transcendental logic may take also a prescriptive position. By investigating the constitution of formal reasoning, transcendental logic, in the Husserlian sense of the term, will take a normative standpoint towards the formal logic(s) and it will put forward criteria for the accuracy of the formal logical systems.

\section{References}

Buridan, J. (2015) Treatise on Consequences. trl. by S. Read. N. Y.

Cohen, H. (1885). Kants Theorie der Erfahrung. $2^{\text {nd }}$ ed. Berlin: Dümmler.

Kemp Smith, N. (1918). Commentary on Kant's Critique of Pure Reason. London: Macmillan.

Kant, I. (1992). Lectures on logic. trl. J. Young. Cambridge University Press.

those who maintain the revisionist interpretation ((van Atten 2015a, 2002) and (Lohmar 2004) among others). Of course this is not to say that Husserl himself did offer a revision of formal logic. In fact as van Atten says:

Clearly, Husserl had no aim of revising classical logic or mathematics; it can however be argued that this has more to do with Husserl's own background and psychology than with what his philosophical principles imply, and that these principles warrant a strong revisionism. (van Atten 2015a: 84) 
Kant, I. (1998). Critique of Pure Reason. trl. P. Guyer and A. W. Wood. Cambridge University Press.

Kern, I. (1964). Husserl und Kant. Netherlands: Springer.

Hartimo, M. (2019). Husserl on Kant and the critical view of logic. Inquiry.

Hartimo, M. (2020). Husserl on 'Besinnung' and Formal Ontology. In F. Kjosavik and C. SerckHanssen (eds.) Metametaphysics andthe Sciences.NewYork and London: Routledge. 200-215

Hopkins, B. (2011). The Origin of the Logic of Symbolic Mathematics. Edmund Husserl and Jacob Klein. Bloomington: Indiana University Press.

Husserl, E. (1913). Logische Untersuchungen, Zweiter Band, I. Teil. Tübingen: Max Niemeyer.

Husserl, E. (1960). Cartesian Meditations, trl. Dorian Cairns. Dordrecht: Springer Science Business Media.

Husserl, E. (1969). Formal and Transcendental Logic. trl. D. Cairns. Netherlands: Martin Nijhoff, The Hague.

Husserl, E. (1973). Experience and Judgment, trl. J. Churchill, and K. Ameriks. London: Routledge.

Husserl, E. (1988). Ideas II. translated by R. Rojcewicz and A. Schuwer.

Husserl, E. (2001). Logical Investigations (2 vols.), trl. J. Findlay, ed. D. Moran, London: Routledge.

Husserl, E. (2002). Logische Untersuchungen. Ergänzungsband. Erster Teil. ed. U. Melle, volume XX/1 of Husserliana. Netherlands: The Hague.

Husserl, E. (2003). Philosophy of Arithmetic, trl. D. Willard. Dordrecht: Kluwer Academic Publishers.

Lohmar, D. (2002). Husserl's concept of categorial intuition, One Hundred Years of Phenomenology: Husserl's Logical Investigations Revisited, Edited by D. Zahavi and F. Stjernfelt. Dordrecht: Springer. 125-145. 
Lohmar, D. (2004). The transition of the principle of excluded middle from a principle of logic to an axiom: Husserl's Hesitant Revisionism in Logic. New Yearbook for Phenomenology and Phenomenological Philosophy, 4:53-68.

Lohmar, D. (2006). Categorial intuition, A Companion to Phenomenology and Existentialism, Edited by H. Dreyfus and M. Wrathal, Oxford: Blackwell, 115-126.

MacFarlane, J. (2002) Frege, Kant, and the Logic in Logicism. The Philosophical Review, Vol. 111, No. 1: 25-65.

Paton, H.J. (1936). Kant's Metaphysic of Experience. London: Macmillan.

Paton, H.J. (1958). Formal and Transcendental Logic. Kant-Studien. 49: 245-263.

Peirce, C. S. (1976). The New Elements of Mathematics: Vol. 4: Mathematical Philosophy. ed. C. Eisele. Mouton De Gruyter.

Shafiei, M. (2019). A Phenomenological Analysis of the Distinction Between Structural Rules and Particle Rules in Dialogical Logic. In C. Weiss (ed.) Constructive Semantics Meaning in Between Phenomenology and Constructivism. Routledge. 85-94.

Shafiei, M. (2018). Meaning and Intentionality. A Dialogical Approach. London: College Publications.

Smith, D. W. (2004) Mind World; Essays in Phenomenology and Ontology. Cambridge University Press.

Smith, D. W. (2013) Husserl. New York and London: Routledge, 2nd edition, revised; 1st edition, 2007.

Sokolowski, R. (1974). Husserlian Meditations. Evanston: Northwestern University Press.

Sokolowski, R. (1981). Husserl's concept of categorial intuition, Philosophical Topics 12 (Supplement) 127-141. 
Tolley, C. (2012). The Generality of Kant's Transcendental Logic, Journal of the History of Philosophy. 50(3): 417-446.

Tugendhat, E. (1967). Der Wahrheitsbegriff Bei Husserl Und Heidegger. Berlin: De Gruyter.

Ueberweg, F. (1874). System der Logik und Geschichte der logischen Lehren. 4th ed.; Bonn: Adolph Marcus.

van Atten, M. (2002). Why Husserl should have been a strong revisionist in mathematics. Husserl Studies, 18(1):1-18.

van Atten, M. (2015a). Essays on Gödel's Reception of Leibniz, Husserl, and Brouwer, Springer. van Atten, M. (2015b). On the fulfilment of certain categorial intentions, The New Yearbook for Phenomenology and Phenomenological Philosophy 13, 173-185. 